\title{
Distribution of cancer stem cells in two human brain gliomas
}

\author{
LILEI PENG ${ }^{1}$, JIE FU ${ }^{2}$, WEIJUN WANG ${ }^{3}$, FLORENCE M. HOFMAN ${ }^{4}$, THOMAS C. CHEN ${ }^{3}$ and LIGANG CHEN ${ }^{1}$ \\ Departments of ${ }^{1}$ Neurosurgery and ${ }^{2}$ Neurology, Affiliated Hospital of Southwest Medical University, \\ Luzhou, Sichuan 646000, P.R. China; Departments of ${ }^{3}$ Neurosurgery and ${ }^{4}$ Pathology, \\ Keck School of Medicine, University of Southern California, Los Angeles, CA 90033, USA
}

Received February 3, 2018; Accepted October 17, 2018

DOI: $10.3892 / \mathrm{ol} .2018 .9824$

\begin{abstract}
There is compelling evidence that brain tumors, particularly glioblastoma multiforme (GBM), harbor a small population of cancer stem cells (CSCs). These CSCs have the ability to undergo self-renewal, initiate tumors in vivo, and are resistant to chemotherapy and radiation therapy. The present study determined the spatial distribution of CSCs within the donated brains of two deceased patients affected by glioblastoma multiforme. The following six grossly visible functional regions were identified: Necrotic tumor, viable solid tumor, infiltrating tumor edge, peritumoral normal brain, normal brain close to the tumor and normal brain distant from the tumor. Each region was snap-frozen, sectioned and immunostained for the CSC biomarkers prominin-1 (CD133) and sex-determining region Y-box 2 (SOX2). The percentages of $\mathrm{CD}_{133^{+}}$and $\mathrm{SOX} 2^{+}$cells within each region were determined. Different percentages of $\mathrm{CD}_{133^{+}}$and $\mathrm{SOX} 2^{+}$cells were identified in different regions. Significantly higher percentages of $\mathrm{CD}_{133}{ }^{+}$and $\mathrm{SOX}_{2}{ }^{+}$cells were indicated at the infiltrating tumor edge when compared with other areas. In summary, the spatial distributions of CSCs in these two brains with glioblastoma multiforme were similar, with the highest concentration being at the infiltrating tumor edge. This suggests that the edge of the tumor is the moving front for tumor progression and invasion, and should be targeted for therapeutic intervention.
\end{abstract}

\section{Introduction}

Glioma is the most common malignant brain tumor in the human central nervous system $(1,2)$. The World Health Organization (3) has defined 4 grades of glioma based on

Correspondence to: Dr Ligang Chen, Department of Neurosurgery, Affiliated Hospital of Southwest Medical University, 25 Taiping Street, Luzhou, Sichuan 646000, P.R. China

E-mail: ligangchen_lgc@163.com

Professor Thomas C. Chen, Department of Neurosurgery, Keck School of Medicine, University of Southern California, 1975 Zonal Avenue, Los Angeles, CA 90033, USA

E-mail: thomas.chen62@yahoo.com

Key words: glioma, cancer stem cells, prominin-1, sex-determining region Y-box 2 histological features: Grade I, pilocytic astrocytoma; grade II, diffuse astrocytoma; grade III, anaplastic astrocytoma; and grade IV, glioblastoma multiforme (GBM). Despite attempts to combine surgery, radiotherapy and chemotherapy, grade III and IV gliomas recur in $>90 \%$ of cases, typically within $2 \mathrm{~cm}$ of the original location, and 10-20\% may develop novel distant lesions (4). Therefore, neuro-oncological research has become focused on overcoming glioma cell resilience against the majority of aggressive treatments, in addition to providing an explanation for the high recurrence rate, particularly in GBM.

Recently, a number of studies have described the presence of a tumor cell subpopulation with stem cell-like properties, known as cancer stem cells (CSCs) (5-9). This population is characterized by self-renewal, a high migration rate, unlimited growth, chemotherapy and radiotherapy resistance, and tumor formation (8). It has been suggested that the clinical behavior of a tumor is largely influenced by CSCs, due to their ability to initiate novel tumors. Therefore, eradicating CSCs may affect stable, long-lasting remission and potentially treat cancer (10-12).

A frequently used biomarker for glioma CSC is prominin-1 [also known as cluster of differentiation 133 (CD133)], a cell surface pentaspan transmembrane glycoprotein, originally identified from murine neuroepithelial cells and located in plasma membrane protrusions (13). A number of studies have indicated that $\mathrm{CD} 133^{+}$cells exhibit a greater tumor-forming ability in immunocompromised rodent brains in vivo compared with CD133 cells. These CD133+ ${ }^{+}$cells form tumors with as little as 100 cells, which is consistent with their high self-renewal ability $(14,15)$. As a subpopulation that is highly resistant to ionizing radiation in human glioma xenografts, $\mathrm{CD} 133^{+}$cells can more effectively repair DNA damage compared with CD133- tumor cells (16). In addition to relative radioresistance, $\mathrm{CD}_{133^{+}}$cells have high expression levels of multiple drug resistance genes compared with the differentiated bulk tumor, and significant resistance to the chemotherapy drugs temozolomide, etoposide, carboplatin and paclitaxel (17-19).

The protein expression of the transcription factor sex-determining region Y-box 2 (SOX2) putatively contributes to cellular invasion in tumors of neural and neural crest origin, including glioma (20). Previous studies have suggested that the overexpression or gene amplification of SOX2 is associated with the development of cancer. The Sox 2 gene in mice has a single exon, but no introns, and is located on chromosome 3q26.3-q27. Sox2 encodes a 317-amino acid protein, which contains a high-mobility group DNA-binding domain (21). 
A

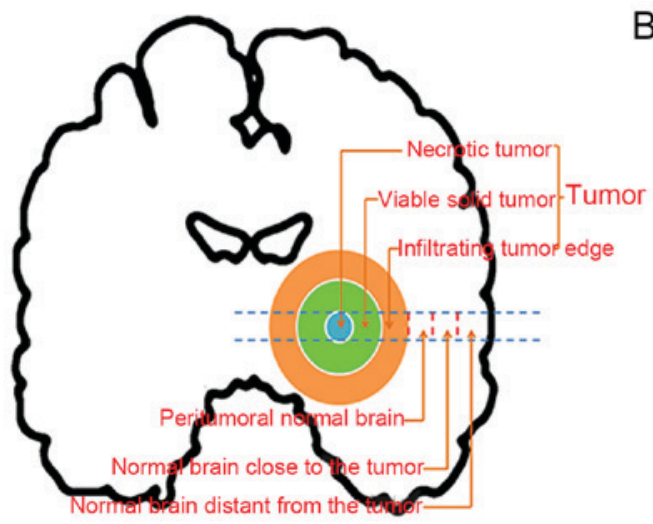

C

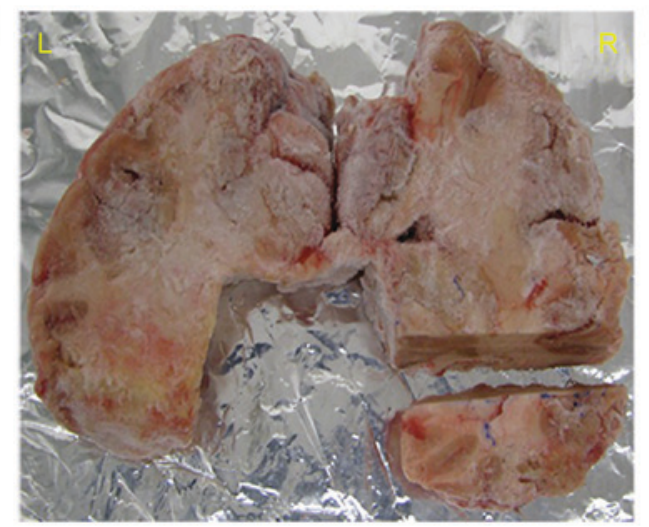

$\mathrm{B}$

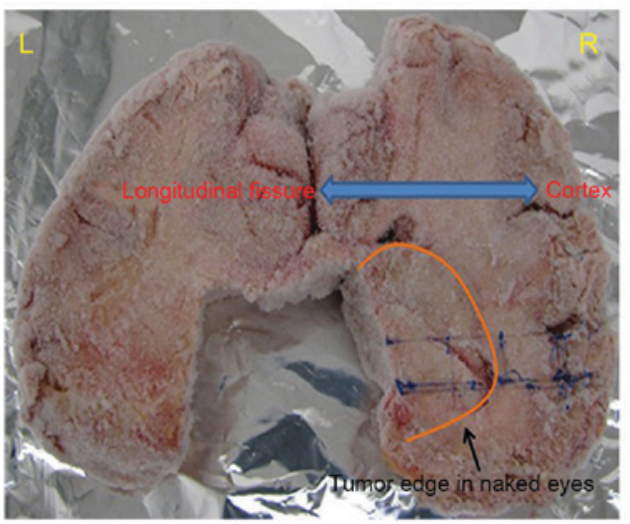

D

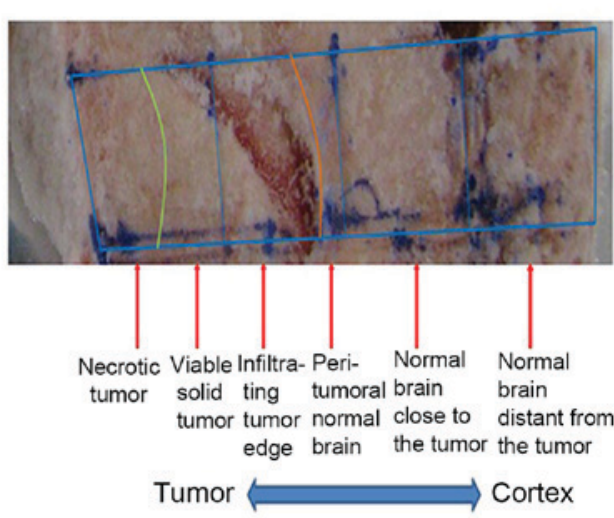

Figure 1. Areas of the whole brain with respect to the GBM tumor. (A) Schematic map of the whole brain with glioma (coronal view). Areas were labeled according to orbital orientation from the center of the tumor outward to the outer boundary of the normal brain. (B) Coronal section of the human brain prior to dissection. (C) A block of human brain tissue with GBM was removed from the whole brain. (D) Areas of the brain tissue identified and labeled. GBM, glioblastoma multiforme.

SOX2 positively contributes to the stemness of cells, which is the ability of cells to self-renew and differentiate into cancer cells, and to the multiple processes of cancer cells $(22,23)$. Silencing Sox 2 in freshly derived glioblastoma tumor-initiating cells prevented their proliferation and inhibited tumorigenicity in immunodeficient mice (24).

While there is considerable literature concerning CSCs, the number and distribution of CSCs in human GBM remains unknown. Even within the same grade of glioma, the reported number of CSCs can vary between $<1$ and $>80 \%$ of the total cell population $(17,25)$. In the present study, it was hypothesized that the discrepancies in results among studies may be due to differences in sampling sites. In particular, the present study investigated whether CSCs can be found in areas of the brain that appear normal.

Therefore, the present study investigated the distribution of CSCs within delimited locations in the glioma and surrounding normal tissues. To the best of our knowledge, this is the first study to quantify systematically the number of CSCs in locations ranging from the tumor center to areas of the brain that appear normal.

\section{Patients and methods}

Patients and tissue samples. Two patients (57-year old male and 65-year old male) with GBM donated their whole brain to the Department of Neurosurgery, University of Southern California (Los Angeles, CA, USA) for scientific research. The
Ethics Committee of the University of Southern California approved the present study and the patients provided prior written informed consent for the use of their brain tissue upon succumbing to the disease. The areas of the brains were labeled according to location, separated into several blocks each, and stored at $-80^{\circ} \mathrm{C}$. Areas of the brain tissue were categorized based on their distance from the necrotic center of the tumor, as follows: Necrotic tumor, viable solid tumor, infiltrating tumor edge, peritumoral normal brain, normal brain close to the tumor, and normal brain distant from the tumor (Fig. 1A). The whole brain was snap-frozen, and the different regions were identified (Fig. 1B). The designated area of the brain was then cut away (Fig. 1C), each individual region cut into pieces (Fig. 1D), and each piece sectioned into $10-\mu \mathrm{m}$ slices on a cryostat.

Immunohistochemical staining. Cryostat sections $(10 \mu \mathrm{m}$ thick) were fixed in $100 \%$ Acetone for $10 \mathrm{~min}$ at room temperature (RT). The slides were immersed and rehydrated 1X PBS three times, 5 min/each, and quenched in endogenous peroxidase in $3 \%$ hydrogen peroxide in $1 \mathrm{x}$ PBS solution for 10 min at RT, and rinsed once. Subsequently, 10\% skimmed milk in 1x PBS was applied and the slides were incubated for 30 min at RT to block non-specific binding. Slides were serially incubated with anti-CD133 mouse monoclonal antibody (cat. no. MAB4310; 1:100; EMD Millipore, Billerica, MA, USA) or anti-SOX2 mouse monoclonal antibody (cat. no. SAB5300177; 1:200; Sigma-Aldrich, Merck KGaA, Darmstadt, Germany) at $4^{\circ} \mathrm{C}$ overnight. Subsequently the slides were incubated with 

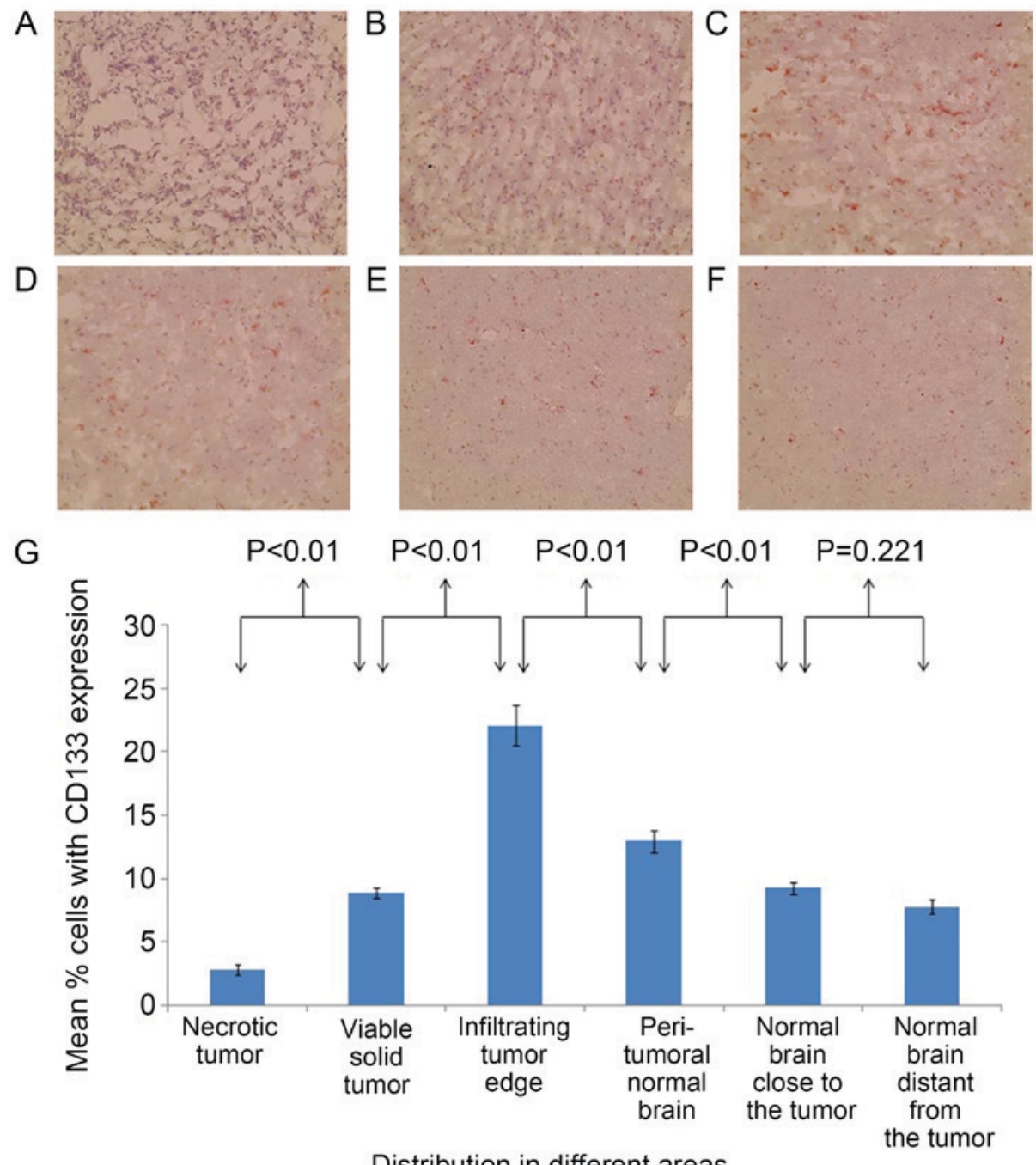

Figure 2. Patient 1: Distribution of CD133+ cells visualized by immunohistochemistry staining for the expression of CD133 in the following different areas of brain tissue: (A) Necrotic tumor, (B) viable solid tumor, (C) infiltrating tumor edge, (D) peritumoral normal brain, (E) normal brain close to the tumor and (F) normal brain distant from the tumor. (G) Bar graph indicating mean percentages of CD133 ${ }^{+}$cells in the frozen sections from different areas of the brain. P-values indicate results of comparisons between adjacent areas. Magnification, x20. CD133, prominin-1.

biotinylated anti-mouse secondary antibody (cat. no. BP-9200; 1:200), anti-ABC (cat. no. PK-7200) and anti-AEC (cat. no. SK-4200) (all from Vector Laboratories, Inc., Burlingame, CA, USA) at RT for $30 \mathrm{~min}$, according to the manufacturer's protocols. Slides were counterstained with hematoxylin for 1-2 min at RT. Similarly, isotype staining with mouse IgG1 negative control antibody (cat. no. CBL610; 1:100; EMD Millipore) was used as the negative control. For a control without antibody, no primary antibody was added and the sections were incubated in $2 \%$ skimmed milk only.

Cell quantification. Photomicrographs of all slides were captured with an EVOS bright-field microscope (magnification, x20). To quantify the number of positive cells per region, 5 random images of each region were taken, and the number of stained cells per total population in each image was counted by eye. The mean percentage of positive cells in the 5 images was calculated and reported as the mean \pm standard error of the mean.

Statistical analysis. The percentages of $\mathrm{CD}_{133^{+}}$and $\mathrm{SOX}_{2}^{+}$ cells for all 6 regions were compared using one-way analysis of variance and Student-Newam-Keuls method. The statistical tests were performed using SPSS 19.0 software (IBM Corp., Armonk, NY, USA). Differences between means were used to determine statistical significance. $\mathrm{P}<0.05$ was considered to indicate a statistically significant difference.

\section{Results}

The different areas of the 2 brains were analyzed for the presence of CSCs by immunostaining for CD133 and SOX2 expression, and the number of $\mathrm{CD}_{13} 3^{+}$and $\mathrm{SOX} 2^{+}$cells was quantified. The 6 areas of the brains analyzed included the necrotic tumor, the viable solid tumor, the infiltrating tumor edge, the peritumoral normal brain, the normal brain close to the tumor and the normal brain distant from the tumor (Fig. 1).

In the brain of patient 1 , the percentages of $\mathrm{CD} 133^{+}$cells (Fig. 2) and SOX2 ${ }^{+}$cells (Fig. 3) were significantly different between all adjacent areas $(\mathrm{P}<0.01)$, with the exception of the percentages of $\mathrm{CD}_{133^{+}}$cells between the normal areas close to and distant from the tumor, which were statistically 

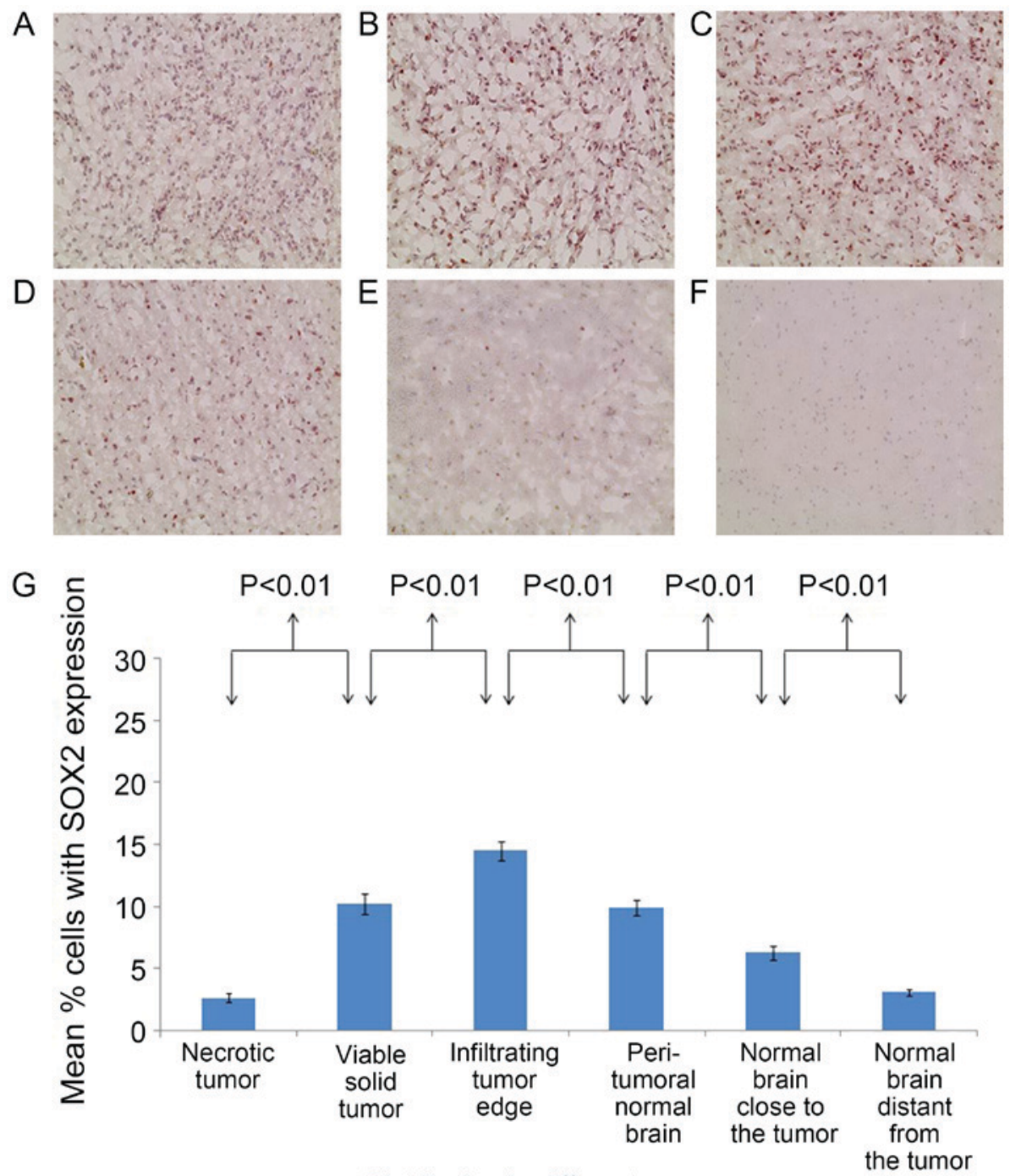

\section{Distribution in different areas}

Figure 3. Patient 1: Distribution of SOX2 $2^{+}$cells visualized by immunohistochemistry staining for the expression of SOX2 in the following different areas of brain tissue: (A) Necrotic tumor, (B) viable solid tumor, (C) infiltrating tumor edge, (D) peritumoral normal brain, (E) normal brain close to the tumor and (F) normal brain distant from the tumor. (G) Bar graph indicating mean percentages of SOX2 $2^{+}$cells in the frozen sections from different areas of the brain. P-values indicate results of comparisons between adjacent areas. Magnification, x20. SOX2, sex-determining region Y-box 2.

similar ( $\mathrm{P}=0.221)$. The percentages of $\mathrm{CD133}{ }^{+}$cells (Fig. 2) and $\mathrm{SOX}^{+}$cells (Fig. 3 ) were significantly higher at the infiltrating tumor edge compared with those at any of the other areas $(\mathrm{P}<0.05)$.

The brain of patient 2 presented with an almost identical distribution of staining results for CSCs as that of patient 1 . In the second brain, the percentages of $\mathrm{CD}_{13} 3^{+}$cells (Fig. 4) and SOX2 ${ }^{+}$cells (Fig. 5) were significantly different between the majority of adjacent areas. However, the percentages of $\mathrm{SOX}^{+}$cells of the peritumoral normal brain and the normal brain close to the tumor were statistically similar, as well as the percentages of $\mathrm{CD}_{133^{+}}$cells and $\mathrm{SOX}_{2}{ }^{+}$cells in the areas close to and distant from the tumor. The percentage of SOX2 ${ }^{+}$ cells in the peritumoral normal brain was significantly higher compared with that of the normal brain distant from the tumor $(\mathrm{P}<0.01)$. The percentages of $\mathrm{CD} 133^{+}$cells (Fig. 4 ) and SOX2 $2^{+}$ cells (Fig. 5) were significantly higher at the infiltrating tumor edge compared with those at any of the other areas $(\mathrm{P}<0.05)$.

The negative controls, without primary antibody or with isotype control, exhibited no significant staining (Fig. 6). In the brains of patient 1 and patient 2 , the percentages of $\mathrm{CD} 133^{+}$ cells and $\mathrm{SOX}_{2}{ }^{+}$cells were highest at the tumor edge, relative to all the other areas. In particular, in the infiltrating tumor edge in patient 1 , the percentages of $\mathrm{CD}_{133^{+}}$cells and $\mathrm{SOX}_{2}{ }^{+}$cells were $22.07 \pm 1.62$ and $14.5 \pm 0.78 \%$, respectively. For patient 2 , the percentages of $\mathrm{CD} 133^{+}$cells and $\mathrm{SOX} 2^{+}$cells in the infiltrating tumor edge were $16.03 \pm 1.29$ and $11.24 \pm 0.76 \%$, respectively.

\section{Discussion}

The importance of CSCs in recurrent gliomas, as well as other solid malignancies, has been studied extensively in previous literature $(8,26-30)$. Therefore, the relevance of identifying the distribution of CSCs within the different regions of the glioma is crucial. The present study indicated, according to the results of the positive staining for CD133 and SOX2 cells, that CSCs are most prevalent at the tumor edge. This suggests that the edge of the tumor is the moving front for tumor progression and invasion, and should be targeted for therapeutic intervention. Surgery and radiotherapy for glioma and even other solid 

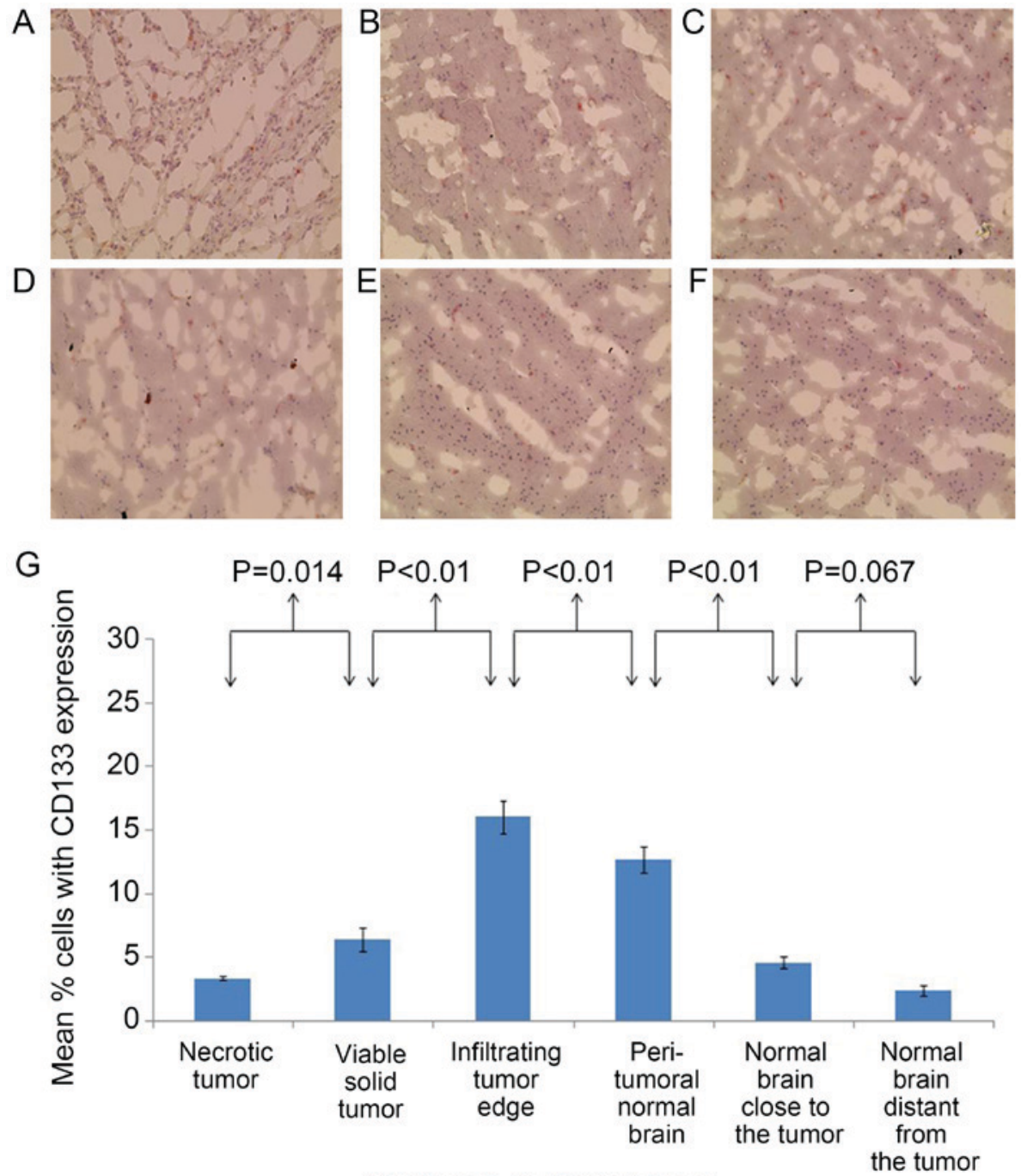

Distribution in different areas

Figure 4. Patient 2: Distribution of $\mathrm{CD}_{133^{+}}$cells visualized via immunohistochemistry staining for the expression of CD133 in the following different areas of brain tissue: (A) Necrotic tumor, (B) viable solid tumor, (C) infiltrating tumor edge, (D) peritumoral normal brain, (E) normal brain close to the tumor and (F) normal brain distant from the tumor. $(\mathrm{G})$ Bar graph indicating mean percentages of CD133 ${ }^{+}$cells in the frozen sections from different areas of the brain. P-values indicate results of comparisons between adjacent areas. Magnification, x20. CD133, prominin-1.

tumors should be focused particularly on the area around the tumor edge. The present study also revealed the presence of $\mathrm{CD}_{133^{+}}$and $\mathrm{SOX}_{2}{ }^{+}$cells in normal brain areas distant from the tumor, which indicates that these CSCs may indicate sites of future progression. Therefore, therapeutic strategies that specifically target CSCs are particularly important.

The findings of the present study suggest that other studies have differed with regard to the concentrations of $\mathrm{CD}_{133}{ }^{+}$and $\mathrm{SOX} 2^{+}$cells found, even for gliomas of the same grade, due to different tumor regions being sampled $(31,32)$. Annovazzi et al (32) examined SOX2 expression in surgical samples from 133 brain gliomas of different grades of malignancy and in cell lines from 16 glioblastomas. This revealed a positive correlation between SOX2 expression and malignancy grade in gliomas and identified that the expression of SOX2 was different at different locations of the brain. In medulloblastomas, SOX2 staining was either positive or negative, according to the occurrence of areas with neuronal differentiation. However, in that study, samples of peritumoral nervous tissue removed from around vascular malformations and other normal brain tissue were obtained from two patients who died following heart attacks. Therefore, the location of the biopsy is crucial.

Although CD133 and SOX2 are the most common markers for CSCs, a number of other immunocytochemical markers have also been used, including nestin and Musashi-1 (33-35). All these markers identify subpopulations of CSCs. In addition, different CD133 and SOX2 antibody clones may recognize CD133 and SOX2 splice variants with epitopes that differ in glycosylation status (36). Therefore, future studies are required for the examination of specific markers. Furthermore, the current study only investigated two specimens as very few patients wish to donate their whole brains for research. However, if possible similar research should be performed with a higher number of specimens to further confirm the conclusion of the present study.

\section{Acknowledgements}

Not applicable. 

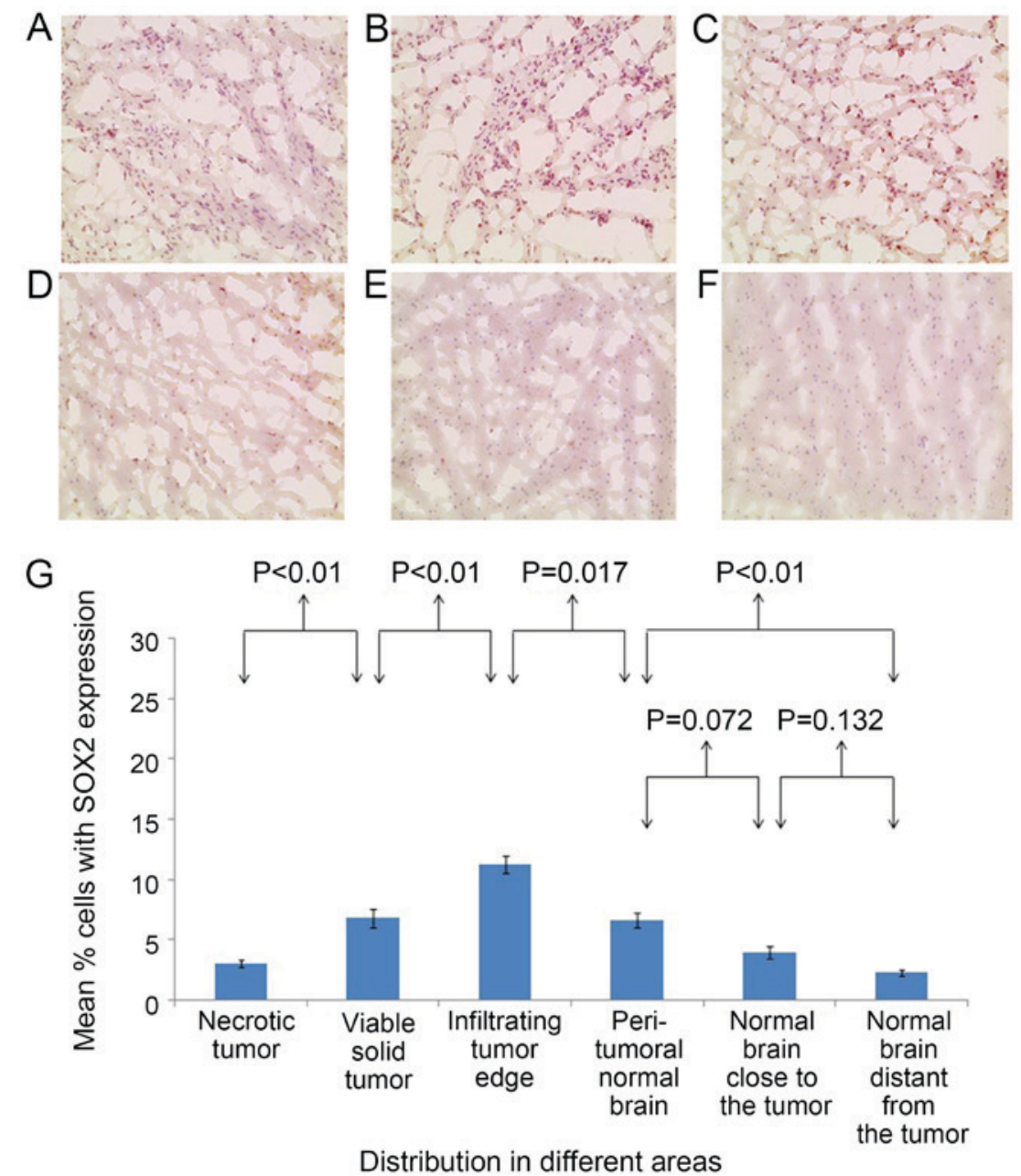

Figure 5. Patient 2: Distribution of SOX2+ cells visualized via immunohistochemistry staining for the expression of SOX2 in the following different areas of brain tissue: (A) Necrotic tumor, (B) viable solid tumor, (C) infiltrating tumor edge, (D) peritumoral normal brain, (E) normal brain close to the tumor and (F) normal brain distant from the tumor. (G) Bar graph indicating mean percentages of SOX2 $2^{+}$cells in the frozen sections from different areas of the brain. P-values indicate results of comparisons between adjacent areas. Magnification, x20. SOX2, sex-determining region Y-box 2.
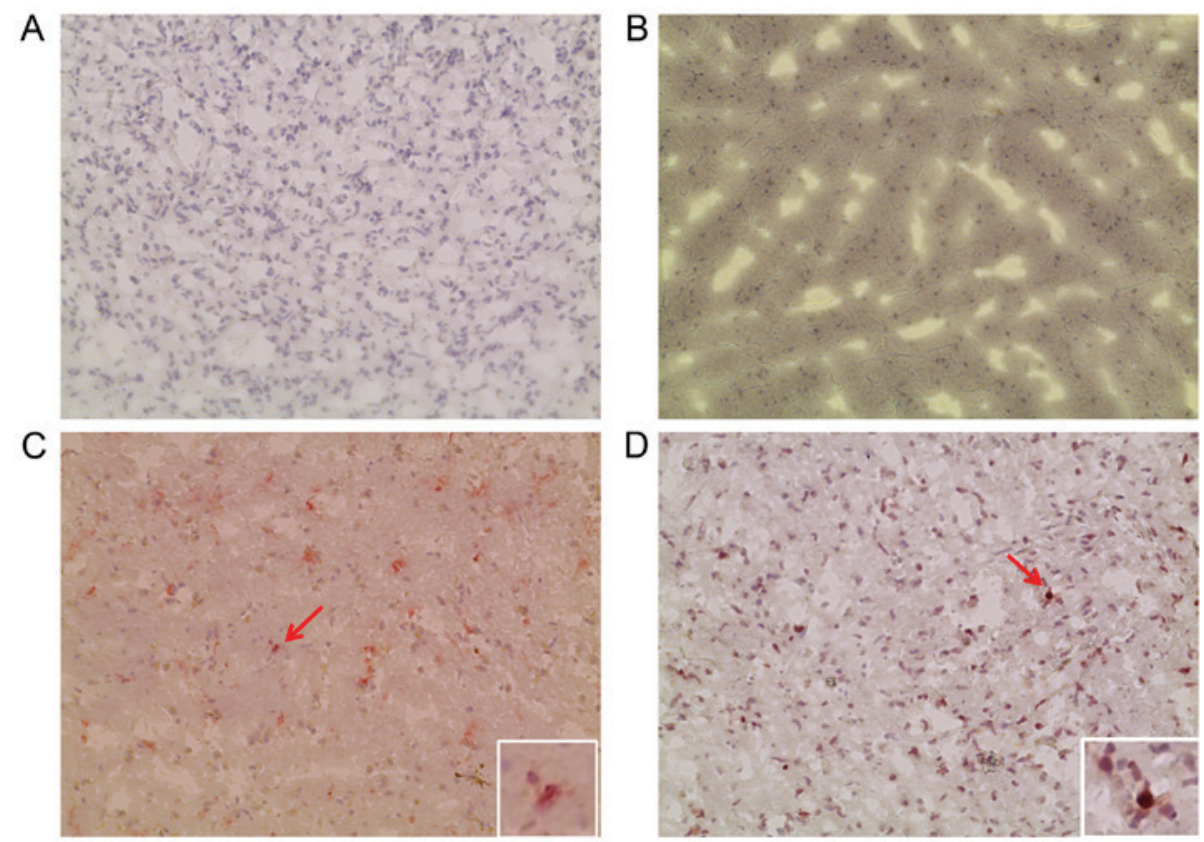

Figure 6. Immunohistochemistry staining of brain tissues. Negative control brain tissues (A) without primary antibody and (B) with isotype control antibody. Staining of the infiltrating tumor edge with (C) CD133 and (D) SOX2. Cells with intense red in the cytoplasm and/or on the membrane were considered CD133 ${ }^{+}$ and $\mathrm{SOX}_{2}{ }^{+}$as indicated by arrows. Magnification of whole image, $\mathrm{x} 20$. Magnification of inset images, $\mathrm{x} 40$. 


\section{Funding}

The present study was supported by the Science and Technology Department of Sichuan Province (grant nos. 2013SZZ002 and 2018JY0404), the Health and Family Planning Commission of Sichuan Province (grant no. 16PJ557), the government of Luzhou (grant nos. 14ZC0071-LH09 and 2016LZXNYD-G03), the Southwest Medical University (grant no. 2013ZRQN068) and the Project Program of Neurosurgical Clinical Research Center of Sichuan Province (grant no. 17082).

\section{Availability of data and materials}

The datasets used and analyzed during the current study are available from the corresponding authors on reasonable request.

\section{Authors' contributions}

Conception and design: LC and TCC. Acquisition of data: LP. Analysis and interpretation of data: LP and JF. Drafting the article: LP and JF. Statistical analysis: LP. Sample collection and handling: WW and FMH. Critical revision of the article: WW and FMH. Reviewing of the submitted version of the manuscript: All authors. Approval of the final version of the manuscript on behalf of all authors: LC and TCC. Study supervision: TCC.

\section{Ethics approval and consent to participate}

The Ethics Committee of the University of Southern California (Los Angeles, USA) approved the present study and the patients provided prior written informed consent for the use of their brain tissues following mortality.

\section{Patient consent for publication}

Not applicable.

\section{Competing interests}

The authors declare that they have no competing interests.

\section{References}

1. Hassan A, Mosley J, Singh S and Zinn PO: A comprehensive review of genomics and noncoding RNA in gliomas. Top Magn Reson Imaging 26: 3-14, 2017.

2. Goodenberger ML and Jenkins RB: Genetics of adult glioma. Cancer Genet 205: 613-621, 2012.

3. Louis DN, Perry A, Reifenberger G, von Deimling A, Figarella-Branger D, Cavenee WK, Ohgaki H, Wiestler OD, Kleihues P and Ellison DW: The 2016 world health organization classification of tumors of the central nervous system: A summary. Acta Neuropathol 131: 803-820, 2016.

4. Brada M, Hoang-Xuan K, Rampling R, Dietrich PY, Dirix LY, Macdonald D, Heimans JJ, Zonnenberg BA, Bravo-Marques JM and Henriksson R, et al: Multicenter phase II trial of temozolomide in patients with glioblastoma multiforme at first relapse. Ann Oncol 12: 259-266, 2001.

5. Jordan CT, Guzman ML and Noble M: Cancer stem cells. N Engl J Med 355: 1253-1261, 2006.

6. Flores DG,LedurPF, Abujamra AL, Brunetto AL, Schwartsmann G, Lenz G and Roesler R: Cancer stem cells and the biology of brain tumors. Curr Stem Cell Res Ther 4: 306-313, 2009.
7. Doherty MR, Smigiel JM, Junk DJ and Jackson MW: Cancer stem cell plasticity drives therapeutic resistance. Cancers (Basel) 8: E8, 2016.

8. Batlle E and Clevers H: Cancer stem cells revisited. Nat Med 23: 1124-1134, 2017.

9. Zhu P and Fan Z: Cancer stem cells and tumorigenesis. Biophys Rep 4: 178-188, 2018.

10. Zhang PY, Yang YJ, Xue Y, Fu J, Zhang CX, Wang Y, Yang Y and Shi H: Cancer stem cells: Targeting tumors at the source. Eur Rev Med Pharmacol Sci 19: 1821-1828, 2015.

11. Pan Q, Li Q, Liu S, Ning N, Zhang X, Xu Y, Chang AE and Wicha MS: Concise review: Targeting cancer stem cells using immunologic approaches. Stem Cells 33: 2085-2092, 2015.

12. Schmohl JU and Vallera DA: CD133, selectively targeting the root of cancer. Toxins (Basel) 8: E165, 2016.

13. Jang JW, Song Y, Kim SH, Kim J and Seo HR: Potential mechanisms of CD133 in cancer stem cells. Life Sci 184: 25-29, 2017.

14. Singh SK, Hawkins C, Clarke ID, Squire JA, Bayani J, Hide T, Henkelman RM, Cusimano MD and Dirks PB: Identification of human brain tumour initiating cells. Nature 432: 396-401, 2004.

15. Beier D, Hau P, Proescholdt M, Lohmeier A, Wischhusen J, Oefner PJ, Aigner L, Brawanski A, Bogdahn U and Beier CP: CD133+ and CD133- glioblastoma-derived cancer stem cells show differential growth characteristics and molecular profiles. Cancer Res 67: 4010-4015, 2007.

16. Bao S, Wu Q, McLendon RE, Hao Y, Shi Q, Hjelmeland AB, Dewhirst MW, Bigner DD and Rich JN: Glioma stem cells promote radioresistance by preferential activation of the DNA damage response. Nature 444: 756-760, 2006.

17. Liu G, Yuan X, Zeng Z, Tunici P, Ng H, Abdulkadir IR, Lu L, Irvin D, Black KL and Yu JS: Analysis of gene expression and chemoresistance of CD133+ cancer stem cells in glioblastoma. Mol Cancer 5: 67, 2006.

18. Tamura K, Aoyagi M, Ando N, Ogishima T, Wakimoto H, Yamamoto M and Ohno K: Expansion of CD133-positive glioma cells in recurrent de novo glioblastomas after radiotherapy and chemotherapy. J Neurosurg 119: 1145-1155, 2013.

19. Niero EL, Rocha-Sales B, Lauand C, Cortez BA, de Souza MM, Rezende-Teixeira P, Urabayashi MS, Martens AA, Neves JH and Machado-Santelli GM: The multiple facets of drug resistance: One history, different approaches. J Exp Clin Cancer Res 33: 37, 2014.

20. Ikushima $\mathrm{H}$, Todo $\mathrm{T}$, Ino $\mathrm{Y}$, Takahashi $\mathrm{M}$, Miyazawa $\mathrm{K}$ and Miyazono K: AutocrineTGF-beta signaling maintains tumorigenicity of glioma-initiating cells through Sry-related HMG-box factors. Cell Stem Cell 5: 504-514, 2009.

21. Scaffidi P and Bianchi ME: Spatially precise DNA bending is an essential activity of the sox 2 transcription factor. J Biol Chem 276: 47296-47302, 2001

22. Liu K, Lin B, Zhao M, Yang X, Chen M, Gao A, Liu F, Que J and Lan X: The multiple roles for Sox 2 in stem cell maintenance and tumorigenesis. Cell Signal 25: 1264-1271, 2013.

23. Kuo HY, Hsu HT, Chen YC, Chang YW, Liu FT and Wu CW: Galectin-3 modulates the EGFR signalling-mediated regulation of Sox 2 expression via c-Myc in lung cancer. Glycobiology 26: 155-165, 2016.

24. Gangemi RM, Griffero F, Marubbi D, Perera M, Capra MC, Malatesta P, Ravetti GL, Zona GL, Daga A and Corte G: SOX2 silencing in glioblastoma tumor-initiating cells causes stop of proliferation and loss of tumorigenicity. Stem Cells 27: 40-48, 2009.

25. Liu W, Shen G, Shi Z, Shen F, Zheng X, Wen L and Yang X: Brain tumour stem cells and neural stem cells: Still explored by the same approach? J Int Med Res 36: 890-895, 2008.

26. Ajani JA, Song S, Hochster HS and Steinberg IB: Cancer stem cells: The promise and the potential. Semin Oncol 1 (Suppl 42): S3-S17, 2015

27. Islam F, Qiao B, Smith RA, Gopalan V and Lam AK: Cancer stem cell: Fundamental experimental pathological concepts and updates. Exp Mol Pathol 98: 184-191, 2015.

28. Sharma A and Shiras A: Cancer stem cell-vascular endothelial cell interactions in glioblastoma. Biochem Biophys Res Commun 473: 688-692, 2016.

29. Pearson AT, Jackson TL and Nor JE: Modeling head and neck cancer stem cell-mediated tumorigenesis. Cell Mol Life Sci 73: 3279-3289, 2016. 
30. Eun K, Ham SW and Kim H: Cancer stem cell heterogeneity: Origin and new perspectives on CSC targeting. BMB Rep 50: 117-125, 2017.

31. Cheng JX, Liu BL and Zhang X: How powerful is CD133 as a cancer stem cell marker in brain tumors? Cancer Treat Rev 35 : 403-408, 2009.

32. Annovazzi L, Mellai M, Caldera V, Valente G and Schiffer D: SOX2 expression and amplification in gliomas and glioma cell lines. Cancer Genomics Proteomics 8: 139-147, 2011.

33. Dahlrot RH, Hermansen SK, Hansen S and Kristensen BW: What is the clinical value of cancer stem cell markers in gliomas? Int J Clin Exp Pathol 6: 334-348, 2013.

34. Dahlrot RH, Hansen S, Jensen SS, Schroder HD, Hjelmborg J and Kristensen BW: Clinical value of CD133 and nestin in patients with glioma: A population-based study. Int J Clin Exp Pathol 7: 3739-3751, 2014.
35. Dahlrot RH: The prognostic value of clinical factors and cancer stem cell-related markers in gliomas. Dan Med J 61: B4944, 2014.

36. Hermansen SK, Christensen KG, Jensen SS and Kristensen BW: Inconsistent immunohistochemical expression patterns of four different CD133 antibody clones in glioblastoma. J Histochem Cytochem 59: 391-407, 2011.

cc) (i) (a) This work is licensed under a Creative Commons Attribution 4.0 International (CC BY-NC 4.0) License 